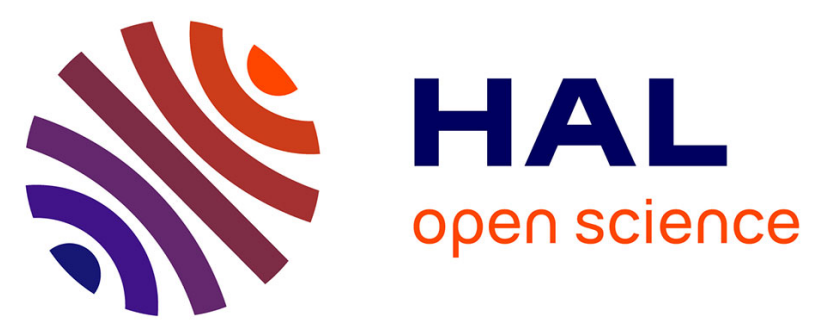

\title{
Linear SAM models for inequality changes analysis: an application to the Extremadurian economy
}

Francisco Javier de Miguel, Jesus Perez-Mayo

\section{To cite this version:}

Francisco Javier de Miguel, Jesus Perez-Mayo. Linear SAM models for inequality changes analysis: an application to the Extremadurian economy. Applied Economics, 2006, 38 (20), pp.2393-2403. 10.1080/00036840500427825 . hal-00581921

\section{HAL Id: hal-00581921 \\ https://hal.science/hal-00581921}

Submitted on 1 Apr 2011

HAL is a multi-disciplinary open access archive for the deposit and dissemination of scientific research documents, whether they are published or not. The documents may come from teaching and research institutions in France or abroad, or from public or private research centers.
L'archive ouverte pluridisciplinaire $\mathbf{H A L}$, est destinée au dépôt et à la diffusion de documents scientifiques de niveau recherche, publiés ou non, émanant des établissements d'enseignement et de recherche français ou étrangers, des laboratoires publics ou privés. 


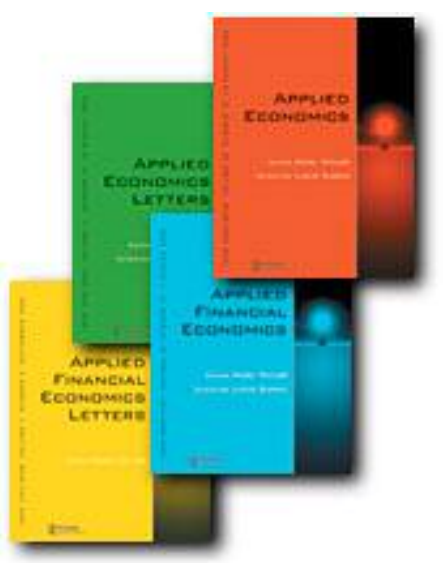

\section{Linear SAM models for inequality changes analysis: an application to the Extremadurian economy}

\begin{tabular}{|c|c|}
\hline Journal: & Applied Economics \\
\hline Manuscript ID: & APE-05-0163.R1 \\
\hline Journal Selection: & Applied Economics \\
\hline $\begin{array}{r}\text { Date Submitted by the } \\
\text { Author: }\end{array}$ & 27-Jul-2005 \\
\hline JEL Code: & $\begin{array}{l}\text { C69 - Other < C6 - Mathematical Methods and Programming < C - } \\
\text { Mathematical and Quantitative Methods, D31 - Personal Income, } \\
\text { Wealth, and Their Distributions < D3 - Distribution < D - } \\
\text { Microeconomics, D59 - Other < D5 - General Equilibrium and } \\
\text { Disequilibrium < D - Microeconomics, H59 - Other < H5 - National } \\
\text { Government Expenditures and Related Policies }<\text { H - Public } \\
\text { Economics, R15 - Econometric and Input Output Models } \mid \text { Other } \\
\text { Models < R1 - General Regional Economics }<\text { R - Urban, Rural, and } \\
\text { Regional Economics }\end{array}$ \\
\hline Keywords: & $\begin{array}{l}\text { social accounting matrices, SAM multipliers, income distribution, } \\
\text { inequality }\end{array}$ \\
\hline
\end{tabular}




\title{
Linear SAM models for inequality changes analysis: \\ an application to the Extremadurian economy
}

\author{
Francisco Javier de Miguel Vélez, Universidad de Extremadura, Department of \\ Applied Economics, Campus universitario, 06071 Badajoz (Spain), \\ demiguel@unex.es \\ Jesús Pérez-Mayo, Universidad de Extremadura, Department of Applied \\ Economics, Campus universitario, 06071 Badajoz (Spain) jperez@unex.es
}

\begin{abstract}
Social accounting matrices are adequate databases for the economic modelling. These matrices emphasize the role of households in the economy, and so, they usually disaggregate the household sector into several groups. This disaggregation allows social accounting matrices to be used for diverse income distribution analysis.

The objective of this work is to use the linear SAM models to study how inequality is modified by several exogenous injections of income. The set of multipliers and indicators presented is applied to the economy of Extremadura - a region situated in the southwest of Spain-. In particular, together with the accounting multipliers, two redistributed income matrices are presented to show how changes in final demand and in income transfers cause opposite effects in inequality. For contrasting these results, we also use Gini and Theil indices. Finally, a major reduction in both would result from an appropriate re-allocation of transfers.

JEL codes: C69, D31, D59, H59, R15
\end{abstract}

Keywords: social accounting matrices, SAM multipliers, income distribution, inequality. 


\section{Introduction}

Inequality measurement is an important topic in the economic literature. However, National Accounting and, more precisely, Social Accounting Matrices have not been widely used as instruments for inequality analysis. This question has already exposed by Atkinson and Bourguignon (2000), who argued that income distribution should be integrate into economic analysis. Some attempts for solving this lack can be found in Rubio and Vicente (2003), where SAM multipliers and inequality measurement were put in touch in a country-level analysis. On the other hand, computable general equilibrium models have been applied to analyse the relationship between economic growth and income inequality -Hanson and Rose (1997)- or the effects on income distribution of several energy taxation measures - Yang (2000).

In this sense, this paper was carried out in the framework of linear SAM modelling. The objective was to apply these models to the economy of Extremadura, in order to quantify and arrange the interdependence relationships, focusing on several results related to households and income inequality.

To attain this objective, together with a brief analysis of traditional SAM multipliers, three applications focused on income distribution analysis are presented. Firstly, two redistributed income matrices are computed. These matrices show the effects that exogenous inflows to either the different activity sectors or the households groups would have on the households' relative incomes. Secondly, Gini and Theil inequality indices are considered to how both indices change because of increases in final demand or in income transfers. Finally, since inequality decrease is an important goal of social policy, we calculated what the redistribution of initial income transfers should be to minimize both inequality indices. 
Particularly worthy of note among the results was that increments in demand and increments in transfers had precisely the opposite effects. The former increased the inequality in income distribution between the different groups of households, while the latter reduced it. In addition, a major reduction in the two inequality indices would result from an appropriate re-allocation of transfers towards the low-income households.

The work is structured as follows. Section 2 presents the linear SAM multipliers in an abridged form, and shows the formulation required to obtain the redistributive multipliers. Section 3 is an overview of the SAM that was constructed for the Extremadura economy, and that will be used as the basis for the subsequent calculations. Section 4 presents the results of the four applications performed. Finally, section 5 gives the principal conclusions drawn from the analyses.

\section{Linear SAM models and redistribution matrix}

Social accounting matrices (SAM) can be conceived of as a disaggregated matrix representation of the circular flow of income, allowing one to study the processes of the generation and distribution of income. These matrices are generally presented as square matrices, with a row and a column identically arranged for each agent or economic sector incorporated in the matrix. By convention, the row entries are interpreted as income, and the column entries as payments or expenditures. An important accounting constraint is that a SAM should satisfy the necessary equality between the sum of each row and the sum of its corresponding column.

Their principal application is as a basis for the construction of economic models. A first group of such models is that of the so-called linear SAM models. These allow one to determine the changes in income levels of the different agents that may be caused by 
possible exogenous shocks. Other indicators may be established based on these multipliers to determine the relative changes in endogenous incomes ${ }^{1}$.

It is important to note that, since it captures in a complete way the interrelationships between the different agents and sectors, this methodology is well suited to evaluating multiplicative effects. In addition, the level of disaggregation that SAMs normally incorporate enables the obtained multipliers to be presented with a high degree of detail. To construct a SAM multiplier model, one must begin by classifying the SAM accounts into endogenous and exogenous. Traditionally, public administrations, the capital or savings/investment account, and the external sector accounts are usually considered exogenous. The accounts for the productive factors, the remaining institutional sectors, and the activity sectors are therefore considered endogenous ${ }^{2}$.

In the formulation of these models, one basically transforms and rewrites the SAM's accounting identities. Assume that the total number of accounts in the SAM, $m$, is apportioned between $n$ endogenous and $k$ exogenous accounts, and that the column vectors $\boldsymbol{y}_{\boldsymbol{n}}$ and $\boldsymbol{y}_{\boldsymbol{k}}$ represent their levels of production or income. Using $\mathbf{A}_{i j}$ to denote submatrices of column-normalized coefficients -expenditure share-, the partitioned matrix structure of the SAM can be expressed in the following manner:

$$
\left(\begin{array}{l}
y_{n} \\
y_{k}
\end{array}\right)=\left(\begin{array}{ll}
A_{n n} & A_{n k} \\
A_{k n} & A_{k k}
\end{array}\right)\left(\begin{array}{l}
y_{n} \\
y_{k}
\end{array}\right)
$$

Computing this matrix product: 


$$
y_{n}=A_{n n} y_{n}+A_{n k} y_{k}=\left(I-A_{n n}\right)^{-1} A_{n k} y_{k}=\left(I-A_{n n}\right)^{-1} x=M a \cdot x
$$

The column vector $\boldsymbol{x}$ shows the sum of exogenous injections received by each endogenous account. The matrix Ma allows one to relate exogenous injections of income with the incomes of the endogenous accounts, providing the termed accounting multipliers ${ }^{3}$.

The SAM multipliers analysis has traditionally focused on determining changes in absolute income levels. It is also important, however, to determine what changes the possible exogenous shocks would cause to the relative position of a given economic agent. The accounting multipliers can be used as the basis to define other measures that capture these relative effects. A good example is found in the redistributive multipliers set forth by Roland-Holst and Sancho $(1992)^{4}$. Following these authors, one defines the relative income vector $\boldsymbol{z}_{\boldsymbol{n}}$ :

$$
z_{n}=y_{n} / e^{\prime} y_{n}
$$

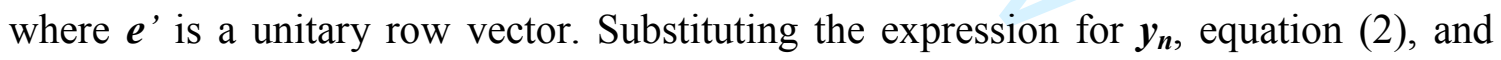
with matrix differentiation, one has:

$$
\begin{aligned}
d z_{n} & =\left(e^{\prime} M a x\right)^{-1}\left[I-\left(e^{\prime} M a x\right)^{-1}(\text { Ma } x) e^{\prime}\right] M a d x= \\
& =\frac{1}{e^{\prime} y_{n}}\left[I-\frac{y_{n}}{e^{\prime} y_{n}} e^{\prime}\right] M a d x=R d x
\end{aligned}
$$


The matrix $\mathbf{R}$, termed redistribution matrix, determines the ultimate distribution of relative incomes resulting from different exogenous shocks. ${ }^{5}$. To show and interpret the redistributive effects more closely, a generic element $\mathrm{R}_{i j}$ can be expressed in the following manner:

$$
R_{i j}=\frac{1}{e^{\prime} y_{n}}\left[M a_{i j}-\frac{y_{n i}}{e^{\prime} y_{n}}\left(e^{\prime} M a_{\cdot j}\right)\right]
$$

where $y_{n i}$ is the $i$-th component of vector $\boldsymbol{y}_{\boldsymbol{n}}$, and $M a_{. j}$ is the $j$-th column of the matrix Ma. One observes that the sign of $R_{i j}$ depends, therefore, on the terms in brackets, i.e., it depends on the relationship between $M a_{i j} /\left(e^{\prime} M a_{. j}\right)$ and $y_{n i} /\left(e^{\prime} y_{n}\right)$.

An exogenous injection received by $j$ account will improve the relative position of agent $i$ if $i$ 's share of the multiplier gains $\left(M a_{i j} /\left(e^{\prime} M a_{. j}\right)\right)$ exceeds its initial share of nominal income, $\left(y_{n i} /\left(e^{\prime} y_{n}\right)\right)$, determining, therefore, a positive value of $R_{i j}$. On the opposite, a negative value of $R_{i j}$ shows a worsening in its relative position.

\section{Social accounting matrix for the Extremadura economy}

To carry out the subsequent applications, we took as the basis the only SAM built for the Extremadura economy, corresponding to the year $1990^{6}$. The set of accounts conforming this matrix (henceforth, SAMEXT90) is presented in figure 1.

The main statistical sources used have been a table of intersectoral flows (input-output table), the corresponding Regional Accounts, and a household's income and expenditure survey. Other more specific sources were also used to complete certain transactions of 
the matrix.

With respect to its disaggregation, firstly, there are two accounts for the labour and capital production factors, that reflect the value added generated in production and its distribution among the eleven household groups. These ones have disaggregated according to different criteria as age, activity sector or income level. Although the households' incomes basically come from the labour and capital factors, they also receive transfers from the government and the external sectors. With these incomes, the households consume, save, and make various payments to the government.

Regarding the activity sectors, their accounting structure is analogous to an input-output table structure. In particular, their cost structure (columns) reflects payments to the labour and capital factors, intermediate inputs, imports, and payments to the government (production and import taxes). Their rows reflect intermediate outputs, private consumption, public consumption, investment, and exports.

Finally, SAMEXT90 also includes an aggregate capital account, reflecting the overall equilibrium between savings and investment; a government account; and three accounts reflecting the relationships between the Extremadura economy and the three differentiated external sectors - rest of Spain, European Community, and rest of the world.

\section{Analysis of the results}

The presented applications are clearly aimed at an income distribution and inequality analysis. We first calculated the accounting multiplier matrix as an application for showing the capacity that the different endogenous agents have to generate increments in income. The following three applications represent the main body of the study, 
analysing the incomes of the different household groups and on their relationships with the production sectors. In this sense, the second application deals with two redistributive effects matrices related to households' relative incomes. The third application emphasizes these results, by simulating increases in final demand and income transfers and assessing the changes in some inequality indices. Finally, the fourth application, in calculating the redistribution of the initial transfers required to minimize two standard inequality indices, shows the importance of transfers as a redistributive instrument.

\subsection{The accounting multipliers matrix}

In our case, the usual closure assumption for SAM multipliers model is used, that is, the accounts for production factors, household groups, and activity sectors are considered as endogenous. Therefore, the corresponding accounting multipliers matrix - Ma (Ext) - is of order $30 \times 30$.

Although one could differentiate various submatrices that carry relevant information, in this section we shall restrict ourselves to analyzing the multipliers calculated as column sums of the matrix Ma(Ext), that we term diffusion effects (backward linkages in inputoutput terms). These multipliers show the overall effects of a unitary exogenous injection received by the endogenous account under consideration on all endogenous account incomes. Thus, agents or sectors with large diffusion effects generate significant knock-on effects, and they could hence be considered as priorities with respect to receiving exogenous impulses from public administrations.

These diffusion effects are given in table 1. It is clear that the greatest effects correspond to the service sectors, especially credit and insurance (account 28) and other salesoriented services (account 29), with a multiplier of approximately five m.u. per received 
exogenous m.u. The farming (account 14) and construction (account 25) sectors also give rise to major income expansion effects. The higher multipliers computed for these activity sectors correspond to a higher interdependence with the rest of endogenous agents. On the other hand, the industrial sector stands out for its small relative weight in the Extremadura economy, and its poor capacity for generating relevant knock-on effects as well (see accounts 18-24).

With respect to the household groups, it is interesting to note that the multipliers for the low-income households are greater than those multipliers of the equivalent high-income groups. This result is due to the lower savings and payments for direct taxation, in relative terms, of low-income households. Consequently, there are also less income leakages to the exogenous part of the model, and so, producing a higher boost to the economic activity by consumption.

\subsection{Redistributed income matrices: activity sectors - households, and households - households}

In this second application, a more detailed analysis was made for two sets of multipliers related to households' incomes. One can define the activities-households multipliers as those that reflect how exogenous injections into the activity sectors affect household incomes. Moreover, the households-households multipliers as those that reflect how those incomes are affected when households receive exogenous inflow income transfers. Using the formalism of section 2, in the following, we use both sets of multipliers to present their corresponding redistributive matrices ${ }^{7}$. The aim is to determine in relative terms for which household groups increments in final exogenous demand or in income transfers are beneficial, and for which they are detrimental. Nevertheless, to facilitate the 
interpretation of the results, instead of the redistribution matrix $R$, we shall present a transformation of $R$ consisting in pre-multiplying it by the term $\left(\boldsymbol{e}^{\prime} \boldsymbol{y}_{\boldsymbol{n}}\right)$. The elements of this new matrix reflect the value of the redistributed income, assuming the value of the endogenous accounts' initial incomes to remain constant ${ }^{8}$.

Specifically, starting from the activities-households submatrix of Ma (Ext), one calculates its corresponding redistributed income matrix (table 2). The last row indicates the redistribution of household income over each sector of activity when there is an increase in its corresponding demand of one m.u. For example, if there is an exogenous increase in the demand for farming goods, 0.091 m.u. of household income would be redistributed: $0.001 \mathrm{~m} . \mathrm{u}$. corresponding to the first households group, 0.026 m.u. to the second, 0.004 m.u. to the sixth, and 0.06 m.u. to the seventh, while the rest of the households' incomes would undergo a relative worsening. One observes that these overall redistributive effects clearly reproduce the diffusion effects presented in table 1 , because the sectors with more significant effects -in our case, a higher redistribution of household income- are again the service sectors (accounts 26-30), followed by farming and construction. The remaining activities, especially the industrial activities, present far smaller total redistributive effects.

It is more interesting to consider the values in the last column. This column represents the mean redistributive effects of a unitary increment in demand. These values are computed as a weighted mean of the row elements, using the shares of exogenous injections of each sector as weights.

One observes that the pattern of relative improvement or worsening showed by the mean effect remains, almost independently of which activity sector receives the exogenous injection. In particular, the results show a worsening in the relative position of the retiree 
household groups (accounts 10-13). That is why their main source of income is government-paid pensions, so the effects that correspond to the distribution of factors incomes among households lack in their chain of interdependence. Similar reasons, namely, a relatively small share of incomes from labour and capital factors, determine a relative worsening for the active low-income households (accounts 3, 5, and 6).

In fact, the only household groups that benefit in relative terms are those of high income. In particular, considering this last column, approximately $66 \%$ of the redistributed income corresponds to account nine (the fifth quintile of active non-farming households), $16 \%$ to account eight (the fourth quintile), $8 \%$ to account seven (third quintile), and $10 \%$ to account four (high-income active farming households). The results thus seem to show that exogenous increases in demand tend to widen even more the differences between low-income and high-income household groups.

Secondly, and to conclude this subsection, we shall consider the households-households multipliers and its corresponding redistributed income matrix (see table 3). The aim is to determine how the relative incomes of households are affected by transfers received by the households themselves.

In contrast to the previous table, one observes a clear predominance of negative signs. The exogenous income transfers only improve the relative position of the household group that received them, so that there are no mutually beneficial linkages (symmetric pairs of positive elements).

Likewise, except for the elements in the main diagonal, for each household group the elements in its corresponding row are very similar, that is, irrespective of the household group that receives the exogenous injection, changes in its relative position are almost the same. On the other hand, although the results show certain homogeneity in the total 
redistribution effects on household incomes, the previous diffusion effects are reproduced again, since the high-income households again show less capacity to generate significant effects than their low-income equivalents.

It is important to note that the results given in the last column (mean redistributive effects) are in the opposite sense to those presented in table $2^{9}$. Specifically, the results logically show that a transfers increase reduce the differences between low and high incomes. Indeed, the lowest income groups are almost the only ones that benefit in their relative positions, especially some of the retiree household groups. The four household groups that previously benefited in relative terms (accounts 4, 7, 8, and 9 in table 2) now show a clear worsening in their relative position.

\subsection{Measuring inequality after final demand and transfers changes}

In this third application, we carried out two sets of simulations that were directly related to the previous redistributed income matrices. The objective of these applications is to confirm the results of the redistributed income matrices, by using the traditional income inequality analysis. Given these matrices, it is expected that, on one hand, increments in final demand increases the inequality level and, on the other one, increments in transfers reduce it. Apart from these qualitative aspects, the inequality indices we employed provide us quantitative information about the effects of growth and transfers on inequality.

Therefore, a first set of simulations was aimed at determining to what degree the levels of inequality are altered by increments in exogenous final demand, and the other the same, but by increments in exogenous income transfers received by households. The trials in both sets of simulations consisted of $10 \%, 20 \%$, and $30 \%$ injections on each 
activity sector and each household group.

In this application, we considered two indices widely used in the literature: the Gini index, and the Theil index. The advantage of using this type of measure is that, since they are functions that assign a real number to each income distribution, they summarize all the information contained in the distribution in a single scalar. The two indices have quite different aggregation procedures, however, and therefore provide numerically distinct results.

The Gini index is probably the most commonly used inequality measure, due to its geometric interpretation and its relationship with the Lorenz curve. It is defined by the following expression:

$$
G=\frac{1}{2 \mu}\left(\frac{1}{n^{2}}\right) \sum_{i=1}^{n} \sum_{j=1}^{n}\left|y_{i}-y_{j}\right|
$$

The Theil index is based on the concept of entropy, and indeed forms part of the general class of entropy measures (Cowell, 1995). It is defined by the following expressions:

$$
\begin{gathered}
T_{c}=\frac{1}{n} \frac{1}{c(c-1)} \sum_{i=1}^{n}\left[\left(\frac{y_{i}}{\mu}\right)^{c}-1\right], c \neq 0,1 \\
T_{0}=\frac{1}{n} \sum_{i=1}^{n} \ln \left(\frac{\mu}{y_{i}}\right), c=0
\end{gathered}
$$

We set the parameter $c$ to zero, to facilitate the optimization programming that will be presented in the next section. 
The simulations results for both indices are presented in tables four and five $\mathrm{e}^{10}$. Beginning with the changes in demand (table 4), the results clearly show that stimulating the demand without making any other adjustment to the Extremadura economy leads to increased inequality ${ }^{11}$. Also, the changes in the two indices become greater, the larger the increment in the demand. It is important to note that these demand increases determine greater income increments for the high-income households. In this sense, due to the different sensitivity of both indices respect to changes in the distribution ${ }^{12}$, one observes that the changes in the Theil index become progressively greater than the corresponding changes in the Gini index.

The results for changes in transfers (table 5) are in the opposite sense to the preceding case: the transfers increments led to reductions in the inequality indices ${ }^{13}$. This was an expected result since the transfers are mainly received by the low-income household groups, thereby narrowing the gap between the values of their nominal income. As in the previous simulations, the different sensitivities of the two indices cause that the changes in the Theil index become progressively greater than the corresponding changes in the Gini index.

To conclude this subsection, it is important to note that the results of these simulations confirm the conclusions drawn from the redistributive effects. In particular, although the techniques of analysis are different, in both cases one observes that increments in final demand or income transfers have contrary effects on the evolution of inequality.

\subsection{Transfers redistribution and inequality minimization}

The importance of income transfers as a redistribution tool has been made clear by the preceding applications. Because of this importance, we propose a re-allocation of 
transfers in order to reduce income inequality. Exogenous transfers are very significant in the Extremadura economy and, besides, social and anti-poverty policies are much decentralized in Spain. Therefore, it is worth to explore the available actions for the regional government.

In particular, instead of increments in transfers, we propose a re-allocation of transfers, remaining constant its overall value ${ }^{14}$. We again used the linear SAM modelling framework showed in equation 2, since transfers redistribution modifies the exogenous inflows that the households receive, and consequently the endogenous incomes vary ${ }^{15}$.

Table 6 gives the two patterns of transfers redistribution that minimize the Gini and the Theil indices. In both cases, the only groups that should receive greater transfers than in the initial situation are the low initial incomes households (accounts 3, 5, 10, and 12), as well as the retiree urban high-income group (account 13). These would therefore be the only beneficiaries of this process of redistribution.

There are slight differences, though, according as to whether the Gini or the Theil index is used. In the former case, the reduction in inequality is smaller; also, other household groups - the second quintile of active non-farming households (account 6) and the higher-income rural retirees (account 11) would receive certain transfers, although less in quantity than the initial values. In the latter case, the sensitivity of the Theil index to changes in the low tail of the distribution leads to greater changes being proposed for the lower-income groups, which in turn leads to a greater reduction of the inequality.

\section{Conclusions}

A set of applications based on the methodological framework of SAM multipliers has been presented for Extremadura. In particular, following the computation of the 
accounting multipliers, the three subsequent applications were focused on income distribution analysis - the fundamental objective of the work. The first of these applications presented the activities-households and households-households redistributive matrices. In the next, straightforward simulations were made to determine how changes in demand or in transfers alter the levels of inequality. In addition, the last application quantified the redistribution of the initial transfers that minimizes the inequality.

The results showed that low-income households have a greater capacity to generate increments in income than their high-income equivalents, although the greatest diffusion effects correspond to the service sectors. In addition, the accounts with the greatest diffusion effects are also those that present the greatest total redistributive effects in the activities-households and households-households redistributed income matrices.

These last two matrices allow one to determine which household groups undergo a relative improvement and which a relative worsening in response to changes in demand or in transfers. The results showed increasing demand or increasing transfers to have opposite effects. In the former, increases in demand led to a relative improvement in high-income households at the cost of those of low income, thus widening the initial gap between the two. In the latter, however, the household groups that improved in relative terms in response to increases in transfers were clearly those of low income.

The simulations reported in the third application again investigated the effects on income distribution of changes in demand or in transfers. The results for the two indices used were coherent with the preceding case.

The last application showed how an appropriate redistribution of the transfers over the household groups allows the initial inequality indices to be significantly reduced. Given 
that the practical entirety of these transfers comes from the public sector, the methodological framework used in the present work could be a valid referent in establishing social policy measures aimed at reducing inequality.

To conclude, we would make two final observations. First, we wish to call the attention of national and regional statistical bodies to the necessity of providing adequate statistical sources. These constitute the numerical support needed for any minimally updated economic analysis to be feasible. Second, we wish to stress the methodological potential of the analysis that has been described in the present work. SAM multipliers have allowed us to obtain important results related to the processes of income distribution and redistribution - results that would previously have been difficult to anticipate and quantify intuitively.

\section{Acknowledgements}

The first author acknowledges the financial support received from Ministerio de Ciencia y Tecnología (SEC2003-06080) and Generalitat de Catalunya (2004XT00095).

\section{References:}

Assane, D. and Grammy, A. (2003) An assessment of the growth and inequality causality relationship, Applied Economic Letters, 10, 871-873.

Atkinson, A.B. and Bourguignon, F. (2000) Introduction: income distributions and economics, in Handbook of Income Distribution, A.B. Atkinson and F. Bourguignon (eds), North-Holland, Amsterdam, 1-86.

Cohen, S. and Tuyl, J. (1991) Growth and equity effects of changing demographic structures in the Netherlands. Simulations within a social accounting matrix, Economic 
Modelling, January, pp. 3-15.

Cowell, F. (1995) Measuring inequality. LSE Handbook in Economics, Prentice Hall, London.

De Miguel, F.J. (2003) Matrices de contabilidad social y modelización de equilibrio general: una aplicación para la economía extremeña, mimeo, University of Extremadura.

De Miguel, F.J. and Manresa, A. (2004) Modelos SAM lineales y distribución de renta: una aplicación para la economía extremeña (Linear SAM models and income distribution: an application to the Extremadura economy), Estudios de Economía Aplicada, 22-3, 577-603.

De Miguel, F.J, Manresa, A. and Ramajo, J. (1998) Matriz de contabilidad social y multiplicadores contables: una aplicación para Extremadura, Estadística Española, 40 (143), 195-232.

Hanson, K. and Rose, A. (1997) Factor productivity and income inequality: a general equilibrium analysis, Applied Economics, 29 (8), 1061-1071.

Isla, F., Moniche, L. and Trujillo, F. (2002) Crecimiento económico y política de transferencias a partir de una matriz de contabilidad social de Andalucía, Estudios de Economía Aplicada, 20 (2), 423-449.

Llop, M. and Manresa, A. (2004) Income distribution in a regional economy: a SAM model, Journal of Policy Modelling, 26 (6), 689-702.

Polo, C., Roland-Holst, D. and Sancho, F. (1990) Distribución de la renta en un modelo SAM de la economía española, Estadística Española, 32 (125), 537-567.

Pyatt, G. and Round, J. (1979) Accounting and fixed price multipliers in a social accounting matrix framework, The Economic Journal, 89, 850-873. 
Reinert, K, Roland-Holst, D. and Shiells, C. (1993) Social accounts and the structure of the North American economy, Economic Systems Research, 5 (3), 295-326.

Roland-Holst, D. (1990) Interindustry analysis with social accounting methods, Economic Systems Research, 2 (2), 125-145.

Roland-Holst, D. and Sancho, F. (1992) Relative income determination in the United States: a social accounting perspective, Review of Income and Wealth, 38 (3), 311-327. Rubio Sanz, M.T. and Vicente Perdiz, J. (2003) SAM multipliers and inequality measurement, Applied Economics Letters, 10, 397-400.

Sen, Amartya (1997) On economic inequality, Oxford University Press, Oxford.

Shorrocks, A.F. (1980) The class of additively decomposable inequality measures, Econometrica, 48, 613-625.

Thorbecke, E. and Jung, H. (1996) A multiplier decomposition method to analyze poverty alleviation, Journal of Development Economics, 48, 279-300.

Yang, H-Y (2000) Carbon reducing taxes and income inequality: general equilibrium evaluation of alternative energy taxation in Taiwan, Applied Economics, 32 (9), 12131221.

\footnotetext{
${ }^{1}$ Social accounting matrices are also typically used to calibrate the parameters of computable general equilibrium models.

${ }^{2}$ There nevertheless exist alternative closure assumptions. See Reinert et al. (1993).

${ }^{3} \mathrm{~A}$ generic element $\mathrm{Ma}_{i j}$ of the said matrix reflects the increment that will accrue in the income of endogenous account $i$ if endogenous account $j$ receives an additional monetary unit of income from the exogenous accounts. For a more detailed analysis of this model, see Pyatt and Round (1979). These authors also present a procedure for the decomposition of the multipliers, giving the necessary existence
} 
conditions of the resulting matrices.

${ }^{4}$ See also Roland-Holst (1990), Polo et al. (1990) and Llop and Manresa (2004). Moreover, Cohen and Tuyl (1991) proposed a different approach for income redistribution analysis, presenting various relative distributive measures. See also, De Miguel and Manresa (2004).

${ }^{5} \mathrm{~A}$ generic element $\mathrm{R}_{i j}$ of the said matrix indicates the direction and magnitude of the change in relative income of account $i$ resulting from a unitary exogenous injection received by account $j$. It can be demonstrated that the different columns of this matrix $\mathrm{R}$ sum to zero, independently of how the distribution is made between endogenous and exogenous accounts. The process of income redistribution could therefore be regarded as a zero-sum game.

${ }^{6}$ Due to the absence of a Regional Statistical Institute, the lack of statistical information is especially serious in Extremadura. These statistical limitations have determined the degree of detail of the SAMEXT90 matrix -it would have been appropriate to disaggregate the labour factor- and have prevented the construction of a SAM referred to a more recent period. For example, it is important to note that there is only one input-output table for the Extremadura economy, also referred to the year 1990. For more detailed information on the Extremadura matrix, see De Miguel, Manresa and Ramajo (1998) and De Miguel (2003).

7 "Elements of the matrix $\mathbf{R}$ are in a one-to-one correspondence with those of the original $\mathbf{M}$ [Ma], and the normalization of incomes can be chosen for the subgroup of endogenous institutions under study." Roland-Holst (1990, pp. 129).

${ }^{8}$ It can be shown that the columns of this redistributed income matrix also sum to zero.

${ }^{9}$ The weights used in this case are those of the exogenous injections received by the different households groups.

${ }^{10}$ Although not presented here for the sake of clarity, these indices can also be calculated by differentiating between active workers (accounts 3-9 in the matrix) and retirees (accounts 10-13). It is also possible to differentiate between high and low incomes directly, i.e., applying the distinction to the active farming-linked households (accounts 1 and 2), the households of active workers in other sectors (accounts 3-7), of rural retirees (groups 8 and 9), and of urban retirees (groups 10 and 11). The results that we obtained in these cases showed the same tendency as described in the text. 
${ }^{11}$ By using a different methodological approach, Assane and Grammy (2003) analyze the causal relationship between growth and inequality.

${ }^{12}$ The Gini index is more sensitive to the changes in the centre of the distribution (Sen, 1997), while the Theil index, with the parameter $c$ set to zero, is more sensitive to changes in the extremes (Shorrocks, 1980).

${ }^{13}$ Indeed, in the initial situation reflected by SAMEXT90, the incorporation of transfers leads to a major reduction in inequality. In particular, the initial Gini and Theil indices for primary incomes are 0.5837 and 0.9456 , respectively, both clearly greater than the final income indices (0.4902 and 0.5131$)$. The reduction in the Theil index is far greater because the transfers fundamentally affect the household groups situated at the lower tail of the distribution.

${ }^{14}$ Isla, Moniche and Trujillo (2002) present a similar analysis for Andalusian economy.

${ }^{15}$ The inequality indices were minimized by solving the corresponding optimization problem, using GAMS (General Algebraic Modelling System) software. 
Figure 1. List of the accounts included in SAMEXT90

Production factors

1. Labour

2. Capital

\section{Households}

3. Younger than 65 , farming sector, low income

4. Younger than 65 , farming sector, high income

5. Younger than 65 , other sectors, 1 st quintile

6. Younger than 65 , other sectors, 2nd quintile

7. Younger than 65 , other sectors, 3rd quintile

8. Younger than 65 , other sectors, 4 th quintile

9 . Younger than 65 , other sectors, 5 th quintile

10. 65 or older, rural, low income

11. 65 or older, rural, high income

12. 65 or older, urban, low income

13. 65 or older, urban, high income

Activity sectors

14. Agriculture

15. Energy

16. Ferrous and non-ferrous minerals and metals

17. Non-metallic minerals
18. Chemical products

19. Metal products and electrical material

20. Transport material

21. Food, beverages, and tobacco industries

22. Textiles, leather, shoes, and clothing

23. Paper and printing

24. Sundry industrial products

25. Construction

26. Recovery and repair, trade and hostelry

27. Transport and communications

28. Credit and insurance institutions

29. Other sales-oriented services

30. Non-sales-oriented services

EXOGENOUS ACCOUNTS (linear SAM model)

31. Capital account (savings/investment)

32. Government

33. External sector: rest of Spain

34. External sector: European Community

35. External sector: rest of the world 
Table 1. Accounting multipliers matrix Ma (Ext): diffusion effects

\begin{tabular}{|l|c|c|l|c|c|}
\hline & Effect & Rank & & Effect & Rank \\
\hline 1 Labour factor & 4.442 & 11 & $\mathbf{1 6}$ Minerals (I) & 1.466 & 28 \\
\hline 2 Capital factor & 4.392 & 14 & $\mathbf{1 7}$ Minerals (I) & 2.532 & 24 \\
\hline 3 Act-farm-low & 4.486 & 9 & $\mathbf{1 8}$ Chemicals & 1.322 & 29 \\
\hline 4 Act-farm-high & 3.336 & 20 & 19 Metal prod. & 2.110 & 26 \\
\hline $\begin{array}{l}\text { 5 Act-nonfarm-1st } \\
\text { quint }\end{array}$ & 4.497 & 8 & 20 Transport material & 1.048 & 30 \\
\hline $\begin{array}{l}\text { 6 Act-nonfarm-2nd } \\
\text { quint }\end{array}$ & 4.413 & 12 & 21 Food ind. & 3.291 & 21 \\
\hline $\begin{array}{l}\text { 7 Act-nonfarm-3rd } \\
\text { quint }\end{array}$ & 3.909 & 16 & 22 Textiles & 1.481 & 27 \\
\hline $\begin{array}{l}\text { 8 Act-nonfarm-4th } \\
\text { quint }\end{array}$ & 3.425 & 19 & 23 Paper and printing & 2.124 & 25 \\
\hline $\begin{array}{l}\text { 9 Act-nonfarm-5th } \\
\text { quint }\end{array}$ & 2.939 & 23 & 24 Sundry ind. & 2.988 & 22 \\
\hline 10 Ret-rural-low & 4.677 & 5 & 25 Construction & 4.449 & 10 \\
\hline 11 Ret-rural-high & 3.707 & 17 & 26 Retail & 4.545 & 7 \\
\hline 12 Ret-urban-low & 4.393 & 13 & 27 Transport & 4.557 & 6 \\
\hline 13 Ret-urban-high & 3.491 & 18 & $\begin{array}{l}\text { 28 Credit and } \\
\text { insurance }\end{array}$ & 5.017 & 1 \\
\hline 14 Farming & 4.802 & 3 & $\begin{array}{l}\text { 29 Other sales } \\
\text { services }\end{array}$ & 4.857 & 2 \\
\hline 15 Energy & 4.088 & 15 & $\begin{array}{l}\text { 30 Non-sales } \\
\text { services }\end{array}$ & 4.788 & 4 \\
\hline MEAN EFFECT & $\mathbf{3 . 5 8 6}$ & & & & \\
\hline
\end{tabular}

Source: the authors. 
Table 2. Redistributed income matrix: activity sectors - households

\begin{tabular}{|c|c|c|c|c|c|c|c|c|c|c|c|c|c|c|c|c|c|c|}
\hline & $\begin{array}{l}\text { Ac } 14 \\
\text { Farm }\end{array}$ & $\begin{array}{l}\text { Ac } 15 \\
\text { Ener }\end{array}$ & $\begin{array}{l}\text { Ac } 16 \\
\text { Min (I) }\end{array}$ & $\begin{array}{c}\text { Ac } 17 \\
\text { Min (II) }\end{array}$ & $\begin{array}{l}\text { Ac } 18 \\
\text { Chem }\end{array}$ & $\begin{array}{l}\text { Ac } 19 \\
\text { Met }\end{array}$ & $\begin{array}{c}\text { Ac 20 } \\
\text { Transp } \\
\text { mat }\end{array}$ & $\begin{array}{l}\text { Ac } 21 \\
\text { Food ind }\end{array}$ & $\begin{array}{l}\text { Ac } 22 \\
\text { Textil }\end{array}$ & $\begin{array}{l}\text { Ac } 23 \\
\text { Paper }\end{array}$ & $\begin{array}{l}\text { Ac 24 } \\
\text { Sund. } \\
\text { ind }\end{array}$ & $\begin{array}{l}\text { Ac } 25 \\
\text { Const }\end{array}$ & $\begin{array}{l}\text { Ac } 26 \\
\text { Retail }\end{array}$ & $\begin{array}{c}\text { Ac } 27 \\
\text { Transp }\end{array}$ & $\begin{array}{l}\text { Ac } 28 \\
\text { Credit } \\
\text { insur. }\end{array}$ & $\begin{array}{l}\text { Ac 29 } \\
\text { Other } \\
\text { serv. }\end{array}$ & $\begin{array}{c}\text { Ac } 30 \\
\text { Non-sales } \\
\text { serv. }\end{array}$ & Mean eff. \\
\hline 3 Act-arm-low & 0.001 & 0.002 & 0.000 & 0.000 & 0.000 & -0.001 & 0.000 & 0.000 & -0.001 & -0.001 & -0.001 & -0.003 & -0.001 & -0.003 & -0.002 & 0.003 & -0.010 & -0.003 \\
\hline 4 Act-farm-high & 0.026 & 0.027 & 0.003 & 0.007 & 0.001 & 0.003 & 0.000 & 0.011 & 0.000 & 0.002 & 0.008 & 0.009 & 0.017 & 0.009 & 0.018 & 0.036 & -0.015 & 0.009 \\
\hline 5 Act-nonfarm-1st q & -0.023 & -0.020 & -0.003 & -0.009 & -0.002 & -0.006 & 0.000 & -0.012 & -0.002 & -0.006 & -0.011 & -0.019 & -0.022 & -0.021 & -0.027 & -0.028 & -0.021 & -0.019 \\
\hline 6 Act-nonfarm-2nd q & -0.017 & -0.018 & -0.002 & -0.004 & -0.001 & -0.001 & 0.000 & -0.007 & 0.001 & 0.000 & -0.004 & -0.002 & -0.009 & -0.002 & -0.009 & -0.024 & 0.020 & -0.002 \\
\hline 7 Act-nonfarm-3rd q & -0.001 & -0.004 & 0.000 & 0.001 & 0.000 & 0.002 & 0.000 & 0.001 & 0.002 & 0.003 & 0.002 & 0.007 & 0.004 & 0.008 & 0.006 & -0.004 & 0.024 & 0.007 \\
\hline 8 Act-nonfarm-4th q & 0.004 & 0.001 & 0.001 & 0.004 & 0.001 & 0.004 & 0.000 & 0.004 & 0.003 & 0.005 & 0.005 & 0.014 & 0.010 & 0.015 & 0.015 & 0.002 & 0.035 & 0.014 \\
\hline 9 Act-nonfarm-5th q & 0.060 & 0.050 & 0.007 & 0.024 & 0.005 & 0.017 & 0.001 & 0.032 & 0.008 & 0.019 & 0.030 & 0.057 & 0.061 & 0.061 & 0.075 & 0.069 & 0.077 & 0.057 \\
\hline 10 Ret-rural-low & -0.026 & -0.022 & -0.003 & -0.010 & -0.002 & -0.007 & 0.000 & -0.014 & -0.003 & -0.008 & -0.013 & -0.024 & -0.026 & -0.025 & -0.032 & -0.030 & -0.031 & -0.024 \\
\hline 11 Ret-rural-high & -0.021 & -0.015 & -0.003 & -0.011 & -0.002 & -0.009 & 0.000 & -0.013 & -0.005 & -0.010 & -0.014 & -0.030 & -0.027 & -0.032 & -0.036 & -0.021 & -0.057 & -0.030 \\
\hline 12 Ret-urban-low & -0.003 & -0.003 & 0.000 & -0.001 & 0.000 & -0.001 & 0.000 & -0.002 & 0.000 & -0.001 & -0.002 & -0.003 & -0.003 & -0.003 & -0.004 & -0.004 & -0.004 & -0.003 \\
\hline 13 Ret-urban-high & 0.000 & 0.002 & 0.000 & -0.001 & 0.000 & -0.002 & 0.000 & -0.001 & -0.001 & -0.002 & -0.002 & -0.006 & -0.004 & -0.006 & -0.006 & 0.002 & -0.018 & -0.006 \\
\hline TOTAL & 0.091 & 0.082 & 0.011 & 0.036 & 0.007 & 0.026 & 0.001 & 0.048 & 0.014 & 0.028 & 0.046 & 0.087 & 0.092 & 0.093 & 0.114 & 0.111 & 0.156 & 0.087 \\
\hline
\end{tabular}
Source: the authors

Table 3. Redistributed income matrix: households - households

\begin{tabular}{|c|c|c|c|c|c|c|c|c|c|c|c|c|}
\hline & $\begin{array}{c}\text { Ac } 3 \\
\text { Act-farm-low }\end{array}$ & $\begin{array}{c}\text { Ac } 4 \\
\text { Act-farm-high }\end{array}$ & $\begin{array}{c}\text { Ac } 5 \\
\text { Act-nonfarm - } \\
1^{\text {st }} \mathbf{q} \\
\end{array}$ & $\begin{array}{c}\text { Ac } 6 \\
\text { Act-nonfarm - } \\
2^{\text {nd }} \mathbf{q} \\
\end{array}$ & $\begin{array}{c}\text { Ac } 7 \\
\text { Act-nonfarm - } \\
3^{\text {rd }} q\end{array}$ & $\begin{array}{c}\text { Ac } 8 \\
\text { Act-nonfarm - } \\
4^{\text {th }} q\end{array}$ & $\begin{array}{c}\text { Ac } 9 \\
\text { Act-nonfarm - } \\
5^{\text {th }} \mathbf{q}\end{array}$ & $\begin{array}{c}\text { Ac } 10 \\
\text { Ret-rural-low }\end{array}$ & $\begin{array}{c}\text { Ac } 11 \\
\text { Ret-rural-high } \\
\end{array}$ & $\begin{array}{c}\text { Ac } 12 \\
\text { Ret-urban-low }\end{array}$ & $\begin{array}{c}\text { Ac } 13 \\
\text { Ret-urban-high }\end{array}$ & Mean eff. \\
\hline 3 Act-arm-low & 0.965 & -0.035 & -0.035 & -0.035 & -0.035 & -0.035 & -0.035 & -0.035 & -0.035 & -0.035 & -0.035 & 0.010 \\
\hline 4 Act-farm-high & -0.060 & 0.935 & -0.060 & -0.060 & -0.062 & -0.064 & -0.066 & -0.058 & -0.063 & -0.059 & -0.064 & -0.033 \\
\hline 5 Act-nonfarm-1st q & -0.052 & -0.047 & 0.948 & -0.052 & -0.049 & -0.047 & -0.045 & -0.053 & -0.049 & -0.052 & -0.048 & 0.072 \\
\hline 6 Act-nonfarm-2nd q & -0.076 & -0.073 & -0.076 & 0.924 & -0.075 & -0.073 & -0.072 & -0.077 & -0.074 & -0.077 & -0.074 & 0.009 \\
\hline 7 Act-nonfarm-3rd q & -0.112 & -0.112 & -0.112 & -0.112 & 0.888 & -0.112 & -0.112 & -0.112 & -0.112 & -0.112 & -0.112 & -0.027 \\
\hline 8 Act-nonfarm-4th q & -0.153 & -0.155 & -0.153 & -0.153 & -0.154 & 0.845 & -0.155 & -0.153 & -0.154 & -0.154 & -0.154 & -0.053 \\
\hline 9 Act-nonfarm-5th q & -0.319 & -0.333 & -0.319 & -0.320 & -0.326 & -0.332 & 0.662 & -0.316 & -0.328 & -0.319 & -0.331 & -0.214 \\
\hline 10 Ret-rural-low & -0.046 & -0.040 & -0.046 & -0.046 & -0.043 & -0.040 & -0.038 & 0.953 & -0.042 & -0.046 & -0.041 & 0.089 \\
\hline 11 Ret-rural-high & -0.106 & -0.100 & -0.106 & -0.105 & -0.103 & -0.100 & -0.098 & -0.107 & 0.898 & -0.105 & -0.101 & 0.113 \\
\hline 12 Ret-urban-low & -0.006 & -0.005 & -0.006 & -0.006 & -0.006 & -0.005 & -0.005 & -0.006 & -0.005 & 0.994 & -0.005 & 0.011 \\
\hline 13 Ret-urban-high & -0.036 & -0.035 & -0.035 & -0.035 & -0.035 & -0.035 & -0.035 & -0.035 & -0.035 & -0.035 & 0.965 & 0.023 \\
\hline TOTAL & 0.965 & 0.935 & 0.948 & 0.924 & 0.888 & 0.845 & 0.662 & 0.953 & 0.898 & 0.994 & 0.965 & 0.327 \\
\hline
\end{tabular}


Table 4. Inequality indices after increments in demand

\begin{tabular}{|c|c|c|c|c|c|c|c|}
\hline & \multirow[t]{2}{*}{$\begin{array}{c}\text { Initial } \\
\text { indices }\end{array}$} & \multicolumn{3}{|c|}{$\begin{array}{l}\text { Final indices after percentage } \\
\text { increments in demand }\end{array}$} & \multicolumn{3}{|c|}{$\begin{array}{l}\text { Percentage variation in indices } \\
\text { after percentage increments in } \\
\text { demand }\end{array}$} \\
\hline & & $10 \%$ & $20 \%$ & $30 \%$ & $10 \%$ & $20 \%$ & $30 \%$ \\
\hline Gini & 0.4902 & 0.4957 & 0.5006 & 0.5050 & 1.1163 & 2.1281 & 3.0263 \\
\hline Theil & 0.5131 & 0.5278 & 0.5413 & 0.5539 & 2.8575 & 5.4963 & 7.9432 \\
\hline
\end{tabular}

Source: the authors.

Table 5. Inequality indices after increments in transfers

\begin{tabular}{|c|c|c|c|c|c|c|c|}
\hline & \multirow[t]{2}{*}{$\begin{array}{l}\text { Initial } \\
\text { indices }\end{array}$} & \multicolumn{3}{|c|}{$\begin{array}{l}\text { Final indices after percentage } \\
\text { increments in transfers }\end{array}$} & \multicolumn{3}{|c|}{$\begin{array}{l}\text { Percentage variation in indices } \\
\text { after percentage increments in } \\
\text { transfers }\end{array}$} \\
\hline & & $10 \%$ & $20 \%$ & $30 \%$ & $10 \%$ & $20 \%$ & $30 \%$ \\
\hline Gini & 0.4902 & 0.4846 & 0.4793 & 0.4742 & -1.1483 & -2.2330 & -3.2591 \\
\hline Theil & 0.5131 & 0.4988 & 0.4859 & 0.4742 & -2.7975 & -5.3127 & -7.5879 \\
\hline
\end{tabular}

Source: the authors.

Table 6. Transfer redistribution for inequality indices minimization

\begin{tabular}{|c|c|c|c|c|c|}
\hline \multirow[b]{2}{*}{ Household groups } & \multirow[b]{2}{*}{ Initial TR } & \multicolumn{2}{|c|}{$\begin{array}{l}\text { Minimization of the } \\
\text { Gini index }\end{array}$} & \multicolumn{2}{|c|}{$\begin{array}{l}\text { Minimization of the } \\
\text { Theil index }\end{array}$} \\
\hline & & New TR & Change (\%) & New TR & Change (\%) \\
\hline 3 Act-arm-low & $8,173,622$ & $12,910,599$ & 57.95 & $21,681,023$ & 165.26 \\
\hline 4 Act-farm-high & $5,088,457$ & 0 & -100 & 0 & -100 \\
\hline 5 Act-nonfarm-1st q & $22,039,063$ & $46,992,092$ & 113.22 & $34,914,618$ & 58.42 \\
\hline $\begin{array}{l}6 \text { Act-nonfarm-2nd } \\
q\end{array}$ & $14,691,296$ & $7,588,633$ & -48.35 & 0 & -100 \\
\hline 7 Act-nonfarm-3rd q & $14,808,748$ & 0 & -100 & 0 & -100 \\
\hline 8 Act-nonfarm-4th q & $17,502,009$ & 0 & -100 & 0 & -100 \\
\hline 9 Act-nonfarm-5th q & $18,395,408$ & 0 & -100 & 0 & -100 \\
\hline 10 Ret-rural-low & $23,994,210$ & $57,679,878$ & 140.39 & $45,440,403$ & 89.38 \\
\hline 11 Ret-rural-high & $39,130,450$ & $25,290,651$ & -35.37 & 0 & -100 \\
\hline 12 Ret-urban-low & $3,085,815$ & $7,826,884$ & 153.64 & $49,063,431$ & 1489.97 \\
\hline 13 Ret-urban-high & $10,479,320$ & $19,099,661$ & 82.26 & $26,288,922$ & 150.86 \\
\hline Gini initial & 0.49 & & & & \\
\hline Gini minimum & 0.42 & & & & \\
\hline Theil initial & 0.51 & & & & \\
\hline Theil minimum & 0.24 & & & & \\
\hline
\end{tabular}

Source: the authors. 
Note: all transfers are given in thousands of pesetas. 